\title{
O IMPACTO DA PRIVATIZAÇÃO NO DESEMPENHO ECONÔMICO: UM ESTUDO EM EMPRESAS BRASILEIRAS DE GRANDE PORTE
}

THE IMPACT OF PRIVATIZATION IN ECONOMIC PERFORMANCE: A STUDY IN BRAZILIAN COMPANIES LARGE

\section{EL IMPACTO DE LA PRIVATIZACIÓN EN DESEMPEÑO ECONÓMICO: UN ESTUDIO EN EMPRESAS BRASILEÑNAS GRANDES}

\section{Vanessa Ingrid da Costa Cardoso}

Mestranda em Administração e Controladoria pela Universidade Federal do Ceará - UFCE E-mail: nessaingrid@gmail.com (Brasil)

\section{Anna Beatriz Grangeiro Ribeiro Maia}

Mestranda em Administração e Controladoria pela Universidade Federal do Ceará - UFCE E-mail: deluxedama@hotmail.com (Brasil)

\section{Sandra Maria dos Santos}

Doutora em Economia pela Universidade Federal de Pernambuco - UFPE

Professora da Universidade Federal do Ceará - UFCE

E-mail: smsantos@ufc.br (Brasil)

\section{Francisco de Assis Soares}

Mestre em Economia pela Universidade Federal do Ceará - UFCE

Professor da Universidade Federal do Ceará - UFCE

E-mail: soares@ufc.br (Brasil) 


\title{
O IMPACTO DA PRIVATIZAÇÃO NO DESEMPENHO ECONÔMICO: UM ESTUDO EM EMPRESAS BRASILEIRAS DE GRANDE PORTE
}

\section{RESUMO}

As privatizações têm destaque na mídia brasileira, representando oportunidades e desafios ao mercado financeiro e alvo de muitos investidores e outros stakeholders. Este estudo contempla o conceito de privatização sob a perspectiva da corrente neoclássica, em que o objetivo primordial da empresa reside na geração de benefícios e retornos aos seus proprietários. O objetivo deste estudo é analisar o comportamento do desempenho econômico das empresas brasileiras frente à privatização. Metodologicamente, realizamos uma pesquisa bibliográfica e documental, com objetivo descritivo e de natureza quantitativa, com realização de teste de diferença entre médias. A amostra constituiu-se por oito empresas brasileiras privatizadas no período de 1990 a 2005, não pertencentes ao setor financeiro. Quatro indicadores de desempenho foram analisados dois anos antes e após a privatização das empresas: Economic Value Added (EVA), Market Value Added (MVA), Return On Assets (ROA) e Return On Equity (ROE). A partir dos resultados constatou-se que as empresas possuem desempenho econômico mais elevado após a privatização, corroborando com estudos anteriores.

Palavras-chave: Privatização; Desempenho Econômico; Corrente Neoclássica.

\section{THE IMPACT OF PRIVATIZATION IN ECONOMIC PERFORMANCE: A STUDY IN BRAZILIAN COMPANIES LARGE}

\begin{abstract}
Privatizations have an important role in the Brazilian media, representing opportunities and challenges on the financial market and the target of many investors and other stakeholders. This study includes the privatization's concept from the neoclassical current, that the primary goals of companies is get and improve benefits and returns to their owners. Therefore, this study aims to analyze the behavior of the economic performance of Brazilian companies before and after the privatization. Then, was done a documentary and bibliographical research, beyondan exploratory and descriptive research, with quantitative analysis. The sample consisted of eight Brazilian companies privatized in the period from 1990 to 2005, outside the financial sector. Four performance indicators were analyzed two years before and two years after the privatization of companies: Economic Value Added (EVA), Market Value Added (MVA), Return On Assets (ROA) and Return On Equity (ROE). From the results it was found that the companies had higher economic performance after the privatization. This results corroborated with other studies.
\end{abstract}

Keywords: Privatization; Economic Performance; Neoclassical Current. 
Vanessa Ingrid da Costa Cardoso, Anna Beatriz Grangeiro Ribeiro Maia, Sandra Maria dos Santos \& Francisco de Assis Soares

\section{EL IMPACTO DE LA PRIVATIZACIÓN EN DESEMPEÑO ECONÓMICO: UN ESTUDIO EN EMPRESAS BRASILEÑAS GRANDES}

\section{RESUMEN}

Privatización han destacado los medios de comunicación de Brasil, lo que representa oportunidades y desafíos para el mercado financiero y en el blanco de muchos inversores y otras partes interesadas. Este estudio contempla el concepto de privatización, desde la perspectiva de la corriente neoclásica en el objetivo principal de la empresa se encuentra en la generación de beneficios y retornos a sus propietarios. El objetivo de este estudio es analizar el comportamiento de los resultados económicos de las empresas brasileñas que enfrentan la privatización. Metodológicamente, realizamos una literatura y los documentos con el objetivo descriptivo y cuantitativo en la naturaleza, con el rendimiento de la prueba de la diferencia entre las medias. La muestra está formada por ocho empresas brasileñas privatizadas en el período de 1990 a 2005, fuera del sector financiero. Cuatro indicadores de resultados se analizaron dos años antes y después de la privatización de las empresas : Valor Económico Agregado (EVA), Mercado de Valor Agregado (MVA), retorno sobre activos (ROA) y rentabilidad sobre recursos propios (ROE). De los resultados se encontró que las empresas tengan un mayor rendimiento económico después de la privatización, lo que corrobora estudios anteriores.

Palabras-clave: Privatización; Los Resultados Económicos; Actual Neoclásico. 
O Impacto da Privatização no Desempenho Econômico: Um Estudo em Empresas Brasileiras de Grande Porte

\section{INTRODUÇÃO}

Seguindo as tendências mundiais de globalização da economia e de eliminação de barreiras à produção e investimento, o Brasil buscou inserir-se nesse processo de transformação por meio da promoção do desenvolvimento via descentralização, flexibilização, desburocratização e reorientação das atividades do setor público (Matos Filho \& Oliveira, 1996). Por exemplo, o Programa Nacional de Desestatização - PND, desde a sua criação até 2011 já contabilizou mais de US\$ 106.005.600.000,00, entre privatizações federais, concessões, privatizações estaduais, entre outros (BNDES, 2011c).

Não obstante a produção científica sobre privatizações já ser relativamente extensa (Sanchis, 1996; Matos Filho \& Oliveira, 1996; Pereira, 1997; Silanes \& La Porta, 1999; Saurin, Mussi \& Cordioli, 2000; Almeida, 2001; Rocha \& Ferreira, 2001; Oliva, 2002; Janoschka, 2002; Pombo \& Ramirez-Gomez, 2003;Anuatti-Neto,Barossi-Filho, Carvalho\& Macedo, 2005; Díaz, 2005), não há uma definição absolutamente consensual do que consiste uma privatização. Assim, é possível encontrar inúmeras definições na literatura especializada, talvez porque, na prática, privatização abrange uma gama variada de fenômenos.Neste estudo consideramos a definição mais ampla de privatização como um processo de transformar uma empresa estatal em privada (Pereira, 1997), e fundamenta-se escola neoclássica utilizando-se por base teórica teoria dos direitos de propriedade, complementada por vezes pela teoria da agência, face ao alcance da eficácia empresarial (Serva, 2003).

Há alguns estudos cujas abordagens abrangeram a relação entre o desempenho das empresas e processos de privatizações, entretanto, com abordagem mais limitada ao período de tempo observado, às variáveis verificadas e aos métodos aplicados para análise. O presente estudo diferencia-se dos demais, pois além de realizar análise gráfica efetua análise estatística, com o teste de diferença entre médias. Além disso, este artigo leva em consideração o desempenho das empresas sob a análise de quatro indicadores: MVA, EVA, ROE e ROA.Assim, a questão-problema que se busca responder é a seguinte: Qual o comportamento do desempenho econômico das empresas brasileiras frente à privatização?Neste sentido, o objetivo geral do presente estudo consiste em analisar o comportamento do desempenho econômico das empresas brasileiras frente à privatização. Para este fim, identificamos as empresas estatais brasileiras que foram privatizadas no período de 1990 a 2005, e identificamos o desempenho econômico das empresas em estudo no período de análise. A pesquisa, de natureza qualitativa e descritiva, utilizou dados secundários levantados nas Demonstrações Financeiras das empresas. Para análise dos dados foi efetuado o teste 
de diferença entre médias, a fim de comparar o desempenho econômico das empresas antes e após a sua privatização. A amostra se constituiu de oito empresas privatizadas no período em estudo.

Neste sentido, a hipótese do presente estudo afirma que a privatização das empresas permite que as mesmas melhores seu desempenho. Delineou-se tal hipótese considerando o desempenho econômico das empresas brasileiras superior após a privatização, tendo em visa que esta tem por finalidade principal o resgate e desenvolvimento empresarial quando a empresa, por má administração estatal está em crise ou em processo de falência (Videira \& Luz, 2009; Andrade, Cunha, Gandra \& Ribeiro, 2001).

A contribuição do presente artigo abrange vários aspectos: 1) baseia-se em um número maior de indicadores de desempenho, com relação a outros estudos realizados, visto que utiliza o MVA, o EVA, o ROE e o ROA; 2) o período de análise se estende até 2011; 3) utiliza informações de domínio público; 4) a amostra inclui somente privatizações que envolveram a alienação de controle e evita o viés de seleção por incluir tanto as grandes como as pequenas empresas, vendas de participações minoritárias e majoritárias, bem como empresas listadas e não listadas; e 5) a análise de detalhada de cada empresa ao longo do tempo.

\section{REVISÃO DA LITERATURA}

\subsection{PRIVATIZAÇÕES NO BRASIL}

Em busca do equilíbrio das contas públicas, e em decorrência dos seguidos fracassos dos planos de estabilização, a noção de que os problemas relativos à inflação e ao crescimento sustentado nas três últimas décadas só seriam solucionados após o devido ajuste das finanças do setor público. Efetivamente, Matos Filho e Oliveira (1996) apresentam alguns fatos que explicam essa deterioração das finanças públicas e o surgimento das privatizações das estatais brasileiras. Entre estes fatos estão o crescimento do setor produtivo estatal, a partir de 1973, financiado por empréstimos externos; a concessão de subsídios creditícios ao setor privado, principalmente ao setor rural, na segunda metade da década de 1970; a elevação da taxa de juros externa, ao final da década de 1970 e nos anos 1980; o financiamento dos déficits na balança comercial por meio de endividamento das estatais, a partir de 1979; os reempréstimos de recursos depositados no Banco Central, na década de 1980, para o pagamento da dívida no exterior; a absorção, pelo Tesouro, das dívidas dos estados e municípios, por ele avalizadas; a desvalorização cambial, como forma de 
O Impacto da Privatização no Desempenho Econômico: Um Estudo em Empresas Brasileiras de Grande Porte

gerar excedentes na balança comercial, em virtude das dificuldades posteriores da entrada de recursos externos na década de 1980, entre outros. Desta forma, as iniciativas de privatização das estatais brasileiras desenvolvem-se a partir da primeira metade da década de 1980, como a principal fonte de recursos não inflacionários para financiamento do déficit público (Matos Junior \& Oliveira, 1996; Pereira, 1997; Serva, 2003).

No Brasil, as primeiras privatizações ocorreram a partir de 1987, quando o BNDES privatizou 16 empresas controladas e outrora inadimplentes com o Banco. Por delegação do governo federal, em 1990, o BNDES foi nomeado gestor do Fundo Nacional de Desestatização FND, depositário legal das ações das empresas incluídas no PND (BNDES, 2011a).No entanto, foi na década de 1990 que as privatizações no Brasil foram impulsionadas através do ambicioso programa de privatização do governo, tornando-se, no fim desta mesma década, o maior programa de privatizações da América Latina (Serva, 2003).Desde a criação do Programa Nacional de Desestatização - PND, em 1991, foram privatizadas 68 empresas e participações acionárias estatais federais, a maioria na siderurgia, química e petroquímica, fertilizantes e energia elétrica. Além dessas, foram repassados à iniciativa privada, por concessão, 7 (sete) trechos da Rede Ferroviária Federal S.A. - RFFSA, as Malhas Oeste, Centro-Leste, Sudeste, Teresa Cristina, Sul, Nordeste, Paulista e um arrendamento para exploração de Contêineres - Tecon-1, Porto de Santos, da Companhia Docas da São Paulo - CODESP, TECON 1, Porto de Sepetiba - CDRJ, Cais de Capuaba - CODESA (Berços 203,204,205), Cais de Paul - CODESA (Berço 206), GERASUL, Terminal roll-on roll-off (CDRJ), Porto de Angra dos Reis (CDRJ), Datamec e Porto de Salvador (CODEBA) (BNDES, 2011b). As privatizações estaduais começaram a ocorrer a partir de 1996. Quando solicitado, o BNDES forneceu assistência técnica na condução dos processos de privatização estaduais (BNDES, 2011a).

Entre 1990 e 2011, o PND contabilizou US\$ 106.005,6 milhões em privatizações (Desestatizações federais, US\$ 71.306,6 milhões; Empresas de Telecomunicações, US\$ 31.174,5 milhões; Privatizações, US\$ 40.025,6 milhões; Concessões, US\$ 106,5 milhões; Privatizações estaduais, US\$ 34.699,0 milhões). A composição total do programa por setores mostra que a privatização do setor elétrico foi responsável por $30 \%$ do valor total dos leilões; telecomunicações, 32\%; siderúrgico, 8\%; mineração, 8\%, petróleo e gás, 7\%; petroquímico, 4\%, financeiro, $6 \%$, transportes, $2 \%$, saneamento, 1\%, Decreto 1.068, 1\%, e outros, 1\% (BNDES, 2011c).O programa progrediu pouco depois de 1998. Entre as razões está o fato de que as privatizações e outras medidas de liberalização coincidiram com um período de lento crescimento da economia, o que enfraqueceu o apoio político ao programa (Anuatti-Neto, Barossi-Filho, Carvalho\& Macedo, 2005). 
Apesar da grande diversidade dos estudos sobre privatização, pode-se agrupá-los de maneira geral em duas vertentes: a corrente neoclássica, em que o objetivo primordial da empresa reside na geração de benefícios e retornos aos seus proprietários; e a escola da política pública, cujo objetivo é o bem estar social de uma dada comunidade (Serva, 2003).De acordo com Serva (2003), a base teórica da economia neoclássica provém da teoria dos direitos de propriedade, complementada por vezes pela teoria da agência e das incitações, ressaltando a relação entre as autoridades máximas (políticos ou executivos do Estado; acionistas majoritários) e os gerentes face ao alcance da eficácia empresarial.Já a escola da política pública baseia-se em grande parte na teoria da escolha pública, se concentrando nos benefícios resultantes da submissão do setor público à disciplina do mercado num processo de maximização da utilidade, o qual se dá no seio de uma determinada coletividade (Serva, 2003).

Esta pesquisa se baseia na corrente neoclássica, visto que seus objetivos centram-se nos interesses dos shareholders e stakeholders das empresas estatais privatizadas, preocupando-se com o desempenho das empresas. Sendo assim, adota a base teórica da economia neoclássica, sendo sustentada pela teoria dos direitos de propriedade e teoria da agência. Apesar das suas dimensões internacionais, no Brasil, o programa brasileiro de privatizações tem recebido pouca atenção da literatura acadêmica (Matos Junior \& Oliveira, 1996; Paula, 1997; Oliva, 2002). Contudo, assim como o estudo de Anuatti-Neto, Barossi-Filho, Carvalho\& Macedo (2005) o presente estudo não faz referência a nenhum estudo específico sobre o programa brasileiro de privatização, mas pesquisas que abordaram a privatização em diversos aspectos, a serem tratados a seguir.

\subsection{ESTUDOS EMPÍRICOS ANTERIORES}

Uma vez apresentada a fundamentação teórica do presente estudo, vale apresentar estudos que contemplem o tema principal deste estudo com abordagens diversas, ou seja, estudos que trataram da privatização e de suas modificações nas empresas que passam por este processo.

Nesse sentido, na busca por classificar os estudos sobre a privatização percebemos que a literatura trata do referido conceito levando em conta cinco enfoques: no país ou região, setores específicos, resultados e desempenho, políticas da privatização e questões gerenciais e organizacionais. A partir da pesquisa bibliográfica, no Quadro 1 são apresentados estudos teóricos e empíricos sobre privatização, seguindo a classificação dada por Serva (2003). 
O Impacto da Privatização no Desempenho Econômico: Um Estudo em Empresas Brasileiras de Grande Porte

\begin{tabular}{|c|c|c|c|c|}
\hline $\begin{array}{l}\text { ENFOCANDO UM } \\
\text { PAÍS OU UMA } \\
\text { REGIÃO }\end{array}$ & $\begin{array}{l}\text { ENFOCANDO } \\
\text { SETORES } \\
\text { ESPECÍFICOS }\end{array}$ & $\begin{array}{l}\text { ENFOCANDO } \\
\text { RESULTADOS E } \\
\text { DESEMPENHO }\end{array}$ & $\begin{array}{c}\text { ENFOCANDO } \\
\text { POLÍTICAS DA } \\
\text { PRIVATIZAÇÃ̃ }\end{array}$ & $\begin{array}{c}\text { ENFOCANDO } \\
\text { QUESTÕES } \\
\text { GERENCIAIS E } \\
\text { ORGANIZACIONAIS }\end{array}$ \\
\hline $\begin{array}{l}\text { Serva (2003); Pombo e } \\
\text { Ramirez-Gomez (2003); } \\
\text { Janoschka (2002);Silanes } \\
\text { e La Porta (1999); } \\
\text { Brouthers e Arens (1999); } \\
\text { Pinheiro e Schneider } \\
\text { (1995); Nolan e } \\
\text { Xiaoqiang (1999); Parker, } \\
\text { (1999); Baer (1994); } \\
\text { Ramamurti (1999); } \\
\text { Labaronne (1998); } \\
\text { Sanchis (1996); Matos } \\
\text { Filho e Oliveira (1996); } \\
\text { Chua (1995); Biondi } \\
\text { (1999); Stanbury (1994); } \\
\text { Bernier (1994). }\end{array}$ & $\begin{array}{l}\text { Almeida (2001); } \\
\text { Dean, Carlisle e } \\
\text { Baden-Fuller } \\
\text { (1999); } \\
\text { Megginson e } \\
\text { Netter (1999); } \\
\text { Welch e Molz } \\
\text { (1999); Paula } \\
\text { (1997); Ennes } \\
\text { (1995). }\end{array}$ & $\begin{array}{l}\text { Castro, Meyer, } \\
\text { Strong e Uhlenbruck } \\
\text { (1996); Pinheiro } \\
\text { (1996); Molz e Hafsi } \\
\text { (1997); Boubakri e } \\
\text { Cosset (1998); } \\
\text { Andrews e Dowling } \\
\text { (1998); Gedajlovic e } \\
\text { Shapiro (1998); } \\
\text { D’Souza e } \\
\text { Megginson (1999); } \\
\text { Saurin, Mussi e } \\
\text { Cordioli (2000); } \\
\text { Rocha e Ferreira } \\
\text { (2001); Anuatti- } \\
\text { Neto, Barossi-Filho, } \\
\text { Carvalho e Macedo } \\
\text { (2005) }\end{array}$ & $\begin{array}{l}\text { Shirley (1999); } \\
\text { Pereira (1997); } \\
\text { Voisin (1995); } \\
\text { Boyco, Shleifer e } \\
\text { Vishny (1996). }\end{array}$ & $\begin{array}{l}\text { Díaz (2005); Oliva } \\
\text { (2002); Özkaya e } \\
\text { Askari (1999); Dorado } \\
\text { e Molz (1998). }\end{array}$ \\
\hline
\end{tabular}

Quadro 1 - Estudos empíricos anteriores

Fonte: Elaborado pelos autores com base na revisão bibliográfica.

$\mathrm{Na}$ literatura sobre privatização e desempenho das Empresas Estatais (EEs), destacam-se: Castro, Meyer, Strong e Uhlenbruck(1996); Pinheiro (1996); Molz e Hafsi (1997); Boubakri e Cosset (1998); Andrews e Dowling (1998); Gedajlovic e Shapiro (1998); D’Souza e Megginson (1999); Saurin, Mussi e Cordioli (2000); Rocha e Ferreira (2001); Anuatti-Neto, Barossi-Filho, Carvalho e Macedo (2005).Castro, Meyer, Strong e Uhlenbruck(1996)identificam as características do processo de privatização da criação de riqueza e distribuição de renda, e descreve as estruturas estatais em um continuum entre corporação governo e agência do governo. Discutem também sobre a eficácia da privatização para os stakeholders, e fornecem exemplos para cada tipo de privatização.

Pinheiro (1996) comparou o desempenho de 50 EEs antes e depois da privatização, usando dados até 1994. Os dados de demonstrações financeiras foram complementados por questionários preenchidos pelas firmas a pedido do BNDES. O estudo cobriu oito variáveis: vendas líquidas, lucro líquido, patrimônio líquido, investimento, investimento fixo, número de empregados, endividamento e um índice de liquidez. Dessas variáveis, foram derivadas outras seis para medir eficiência: vendas e lucro por empregado, a taxa de retorno na forma de lucro sobre vendas e sobre patrimônio líquido, e a propensão a investir, tanto em relação às vendas como ao patrimônio. Nenhum controle foi feito para as flutuações macroeconômicas, efeitos de agências regulatórias e 
listagem em bolsa. Por fim, o autor concluiu que as privatizações aumentam a produção, a eficiência, a lucratividade, a propensão a investir, reduzem o emprego e melhoram os indicadores financeiros das empresas.

Molz e Hafsi (1997)classificaram a privatização basicamente de duas formas: a) transferência de uma empresa em funcionamento ou dos ativos de uma empresa de um proprietário do setor público a um proprietário do setor privado; b) transformação de uma organização de propriedade do Estado ou de uma administração fornecedora de um serviço público em uma organização autônoma cujo desempenho é avaliado mediante critérios baseados no mercado.

Boubakri e Cosset (1998) descreveram o fenômeno da privatização, os objetivos dos governos que privatizaram empresas, as características dos programas de privatização e resume a evidência empírica sobre o desempenho financeiro e as operações das empresas recém-privatizadas. Os resultados de Boubakri e Cosset (1998) sugerem que a privatização tem mantido suas promessas. Mais especificamente, as empresas recém-privatizadas aumentaram a sua rentabilidade e eficiência, sem sacrificar o emprego. Estas promessas parecem principalmente ter sido realizada em países em desenvolvimento de renda média alta. Como sugestão de pesquisa futura, os autores (1998) advertem que seria o de avaliar o desempenho do mercado de empresas recém-privatizadas, bem como determinar se existe uma relação entre a contabilidade eo desempenho das empresas recém-privatizadas.

Andrews e Dowling (1998) buscaram identificar as escolhas estratégicas que diferenciam as empresas com desempenho superior pós-privatização daquelas com desempenho inferior pósprivatização. Sob à luz da teoria da agência, as hipóteses associadas ao desempenho superior pósprivatização levantadas pelos autores foram: (1)o governo não manter uma participação significativa de ações; (2) mudanças nas chefias; (3)opções de ações de gestão sendo iniciadas; (4) redução no número de funcionários; e (5) a companhia sendo reestruturada financeiramente. A amostra foi composta por 41 empresas privatizadas de seis classificações de indústrias de 15 países. Considerando o tamanho, tipo de indústria e país (efeitos econômico-regulatórios) as hipóteses são suportadas, exceto pela relação com o número de funcionários.

Gedajlovic e Shapiro (1998) analisaram empiricamente a relação entre a concentração de propriedade e de rentabilidade entre as nações do Canadá, França, Alemanha, Reino Unido e Estados Unidos. Os resultados indicam que as diferenças estatisticamente significativas de fato existem em todos os países estudados. Essencialmente, os autores argumentam que a correlação entre a concentração de propriedade e de rentabilidade empresa difere entre os países de uma forma sistemática, determinada pelo sistema nacional de governança corporativa. 
O Impacto da Privatização no Desempenho Econômico: Um Estudo em Empresas Brasileiras de Grande Porte

D’Souza e Megginson (1999) compararam o desempenho pré-privatização e pósprivatização financeira e operacional de 85 empresas de 28 países industrializados que foram privatizadas por meio de ofertas públicas de ações entre 1990 e 1996. Os autores apontaram aumentos significativos na rentabilidade, produção, eficiência operacional e pagamentos de dividendos - e diminuições significativas nos índices de alavancagem - para a amostra total de empresas após a privatização; as despesas de capital aumentaram significativamente em termos absolutos, mas não em relação às vendas; ocorreram declínios de emprego, mas não significativos. Por fim, sugerem, diante dos resultados, que a privatização produz melhorias significativas de desempenho.

Saurin, Mussi e Cordioli (2000) analisaram o desempenho econômico das empresas estatais privatizadas com base no EVA - Valor Econômico Agregado (Economic Value Added) e no MVA Valor de Mercado Agregado (Market Value Added). Ambos são indicadores econômicos que estão relacionados diretamente ao capital investido pela empresa. O primeiro caracteriza a rentabilidade real da empresa, ou seja, como capital é empregado em cada operação da mesma e o último mede o valor em toda a sua trajetória. São apresentados os cálculos do EVA e do MVA das empresas estatais privatizadas no período de 1991 a 1997, e a respectiva análise dos resultados obtidos. Os autores concluem uma das expectativas básicas do Programa Nacional de Privatização, qual seja apresentar melhorias na sua situação econômico-financeira, refletidas na lucratividade e rentabilidade, não fora atendida. Os testes realizados na amostra não demonstraram a ascendência do EVA e MVA, o que era esperado. Quanto à existência da correlação entre EVA e MVA, pôde-se observar, empiricamente, a correlação positiva esperada entre os índices.

Já o estudo de Rocha e Ferreira (2001) discutiu o desempenho inovador de dois grupos de empresas brasileiras participantes da base de dados da Associação Nacional de Pesquisa e Desenvolvimento das Empresas Industriais (Anpei): um grupo composto por empresas privatizadas e um grupo geral de empresas. A análise comparativa baseou-se nos indicadores de inovação tecnológica produzidos pela Anpei e se referem ao período 1994 a 1998, tendo construído seus indicadores sob as orientações do Manual de Oslo-OCDE, as quais produzem informações relevantes no sentido de contribuir para maior compreensão do processo de inovação no âmbito das empresas. Embora as amostras pesquisadas não sejam ideais, os indícios fornecidos pela pesquisa vão contra a ideia geral de que a privatização se tenha constituído um mecanismo suficiente para dinamizar o desenvolvimento tecnológico das empresas, e os autores atentam para o fato de que as empresas privatizadas manifestarem opção mais forte pela compra de tecnologia, em vez de reforçar seus projetos estratégicos de geração autônoma de inovações. 
Posteriormente, Pombo e Ramirez-Gomez (2003) analisaram o desempenho das empresas privatizadas colombianas. Os autores descreveram o programa de privatização realizado no setor produtivo da economia colombiana na década de 1990, e avaliaram a privatização dentro do contexto da política de desregulamentação do mercado em geral e a promoção do investimento privado na provisão de infraestrutura pública e domiciliar dos serviços públicos. Dois estudos de caso são explorados: os setores de fabricação e de energia. O artigo realiza uma análise econométrica de um conjunto de indicadores operacionais e de reestruturação de desempenho para as empresas privatizadas. Os resultados sugerem que a privatização e a entrada de concorrência tiveram um efeito positivo sobre a eficiência dos serviços públicos privatizados e investimento. O principal resultado mostra que os núcleos de eficiência melhoraram após a reforma e que a política de regulamentação tem tido um efeito positivo na eficiência produtiva.

Anuatti-Neto et al. (2005) tem seu foco no efeito da privatização sobre as empresas privatizadas no Brasil. A amostra e extensiva incluindo todas as empresas do setor produtivo privatizadas desde 1991, para as quais foi possível encontrar demonstrações financeiras. Os autores examinaram um conjunto de 15 indicadores de desempenho. Por meio de uma análise de dados em painel, capturaram os efeitos da privatização sobre o desempenho das empresas privatizadas, controlando efeitos importantes como flutuações macroeconômicas, regulação, listagem em bolsa, atuação em setores tradable, ou comercializáveis, participação minoritária do governo no bloco de controle e reestruturação anterior à privatização. Por fim, os autores detectaram: um aumento na lucratividade e na eficiência operacional destas empresas; que a perda do suporte financeiro do estado também implica um ajuste financeiro por meio do aumento da liquidez corrente e redução do endividamento de longo prazo; e que os efeitos sobre investimento, produção e pagamento de dividendos e impostos são menos claros.

\section{METODOLOGIA}

O estudo empírico visa analisar o desempenho econômico das companhias brasileiras privatizadas, antes e após a privatização. Metodologicamente, esta pesquisa é descritiva (Richardson, Peres, Wanderley, Correia\& Peres, 2009) e de natureza quantitativa. Objetivou-se descrever as principais características do processo de privatização das empresas estatais brasileiras privatizadas, analisando como evolui o seu desempenho, antes e depois da privatização. Classificase, ainda, como uma pesquisa bibliográfica e documental (GIL, 2008), nomeadamente incorporando 
O Impacto da Privatização no Desempenho Econômico: Um Estudo em Empresas Brasileiras de Grande Porte

o levantamento das informações das empresas estatais brasileiras que foram privatizadas. Marconi e Lakatos (2002) salientam que a pesquisa bibliográfica busca colocar o pesquisador em contato direto com o que já foi escrito, dito ou filmado sobre determinado tema. A fonte documental é secundária constituída de demonstrações contábeis disponíveis no website das empresas do estudo e de informações contidas na base de dados Economática®.

\subsection{AMOSTRA}

Para viabilização do estudo, foram pesquisadas as empresas brasileiras não financeiras privatizadas no período entre 1990 e 2005. Optou-se por não analisar as empresas do setor financeiro por estas possuírem características que não comparáveis às empresas não financeiras. Nesta mesma vertente, Cooke (1989) sugeriu ser apropriado excluir da amostra o setor financeiro visto as particularidades de suas operações. Adicionalmente, todas as instituições financeiras privatizadas foram adquiridas por outras instituições financeiras, dificultando a observação do desempenho individual da empresa privatizada.

Os dados coletados e analisados referem-se aos exercícios que antecederam e sucederam a privatização das empresas. Assim como efetuado na pesquisa de Anuatti-Neto, Barossi-Filho, Carvalho e Macedo(2005), o presente estudo considera um período de defasagem de dois anos para a avaliação do desempenho. Assim, a análise é efetuada nos dois anos anteriores à privatização e nos dois anos seguintes à privatização.O Quadro 2 apresenta as 48 empresas que foram privatizadas no período entre 1990 e 2005.

\begin{tabular}{|c|l|c|c|l|c|}
\hline REF & \multicolumn{1}{|c|}{ EMPRESA } & $\begin{array}{c}\text { DATA DE } \\
\text { PRIVATIZAÇÃO }\end{array}$ & REF & \multicolumn{1}{|c|}{ EMPRESA } & $\begin{array}{c}\text { DATA DE } \\
\text { PRIVATIZAÇÃO }\end{array}$ \\
\hline 1 & Bco do Estado do Ceará S.A. & 21.12 .2005 & 25 & Petroquímica União S.A. & 25.01 .1994 \\
\hline 2 & $\begin{array}{l}\text { Bco do Estado do Maranhão } \\
\text { S.A. }\end{array}$ & 10.02 .2004 & 26 & Aço Minas Gerais S.A. & 10.09 .1993 \\
\hline 3 & $\begin{array}{l}\text { Bco do Estado do Amazonas } \\
\text { S.A }\end{array}$ & 24.01 .2002 & 27 & $\begin{array}{l}\text { Companhia Siderúrgica } \\
\text { Paulista }\end{array}$ & 20.08 .1993 \\
\hline 4 & Bco do Estado de Goiás S.A. & 04.12 .2001 & 28 & $\begin{array}{l}\text { Ultrafértil S.A. Indústria e } \\
\text { Comércio de Fertilizantes }\end{array}$ & 24.06 .1993 \\
\hline 5 & Bco do Estado da Paraíba S.A. & 08.11 .2001 & 29 & $\begin{array}{l}\text { Companhia Siderúrgica } \\
\text { Nacional }\end{array}$ & 02.04 .1993 \\
\hline
\end{tabular}


Vanessa Ingrid da Costa Cardoso, Anna Beatriz Grangeiro Ribeiro Maia, Sandra Maria dos Santos \& Francisco de Assis Soares

\begin{tabular}{|c|c|c|c|c|c|}
\hline 6 & $\begin{array}{l}\text { Bco do Estado de São Paulo } \\
\text { S.A. }\end{array}$ & 20.11.2000 & 30 & $\begin{array}{l}\text { Fábrica de Estruturas } \\
\text { Metálicas S.A. }\end{array}$ & 02.04 .1993 \\
\hline 7 & Bco do Estado do Paraná S.A. & 17.10.2000 & 31 & $\begin{array}{l}\text { Companhia. Aços Especiais } \\
\text { Itabira }\end{array}$ & 23.10 .1992 \\
\hline 8 & $\begin{array}{l}\text { Datamec S.A. - Sistemas de } \\
\text { Processamento de Dados }\end{array}$ & 23.06.1999 & 32 & Acesita Energética S.A. & 23.10 .1992 \\
\hline 9 & Bco do Estado da Bahia S.A. & 22.06 .1999 & 33 & Forjas Acesita S.A. & 23.10 .1992 \\
\hline 10 & $\begin{array}{l}\text { Bco do Estado de Pernambuco } \\
\text { S.A. }\end{array}$ & 17.11.1998 & 34 & Goiás Fertilizantes S.A. & 08.10 .1992 \\
\hline 11 & $\begin{array}{l}\text { Centrais Geradoras do Sul do } \\
\text { Brasil S.A. }\end{array}$ & 15.09.1998 & 35 & $\begin{array}{l}\text { Fertilizantes Fosfatados } \\
\text { S.A }\end{array}$ & 12.08.1992 \\
\hline 12 & $\begin{array}{l}\text { Bco do Estado de Minas } \\
\text { Gerais S.A. }\end{array}$ & 14.09.1998 & 36 & $\begin{array}{l}\text { Companhia Siderúrgica de } \\
\text { Tubarão }\end{array}$ & 23.07.1992 \\
\hline 13 & TELEBRÁS & 29.07.1998 & 37 & $\begin{array}{l}\text { Companhia Nacional de } \\
\text { Álcalis }\end{array}$ & 15.07.1992 \\
\hline 14 & Bco Meridional do Brasil S.A. & 04.12 .1997 & 38 & $\begin{array}{l}\text { Álcalis do Rio Grande do } \\
\text { Norte }\end{array}$ & 15.07.1992 \\
\hline 15 & $\begin{array}{l}\text { Bco de Crédito Real de Minas } \\
\text { Gerais S.A. }\end{array}$ & 07.08 .1997 & 39 & $\begin{array}{l}\text { Companhia Petroquímica } \\
\text { do Sul }\end{array}$ & 15.05 .1992 \\
\hline 16 & $\begin{array}{l}\text { Bco do Estado do Rio de } \\
\text { Janeiro S.A }\end{array}$ & 26.06.1997 & 40 & $\begin{array}{l}\text { Petroflex Indústria e } \\
\text { Comércio S.A. }\end{array}$ & 10.04.1992 \\
\hline 17 & Companhia Vale do Rio Doce & 06.05.1997 & 41 & Aços Finos Piratini S.A & 14.02 .1992 \\
\hline 18 & $\begin{array}{l}\text { Light Serviços de Eletricidade } \\
\text { S.A. }\end{array}$ & 21.05 .1996 & 42 & $\begin{array}{l}\text { Serviço de Navegação da } \\
\text { Bacia do Prata }\end{array}$ & 14.01.1992 \\
\hline 19 & $\begin{array}{l}\text { Espírito Santo Centrais } \\
\text { Elétricas S.A. }\end{array}$ & 11.07.1995 & 43 & $\begin{array}{l}\text { Companhia Siderúrgica do } \\
\text { Nordeste }\end{array}$ & 14.11.1991 \\
\hline 20 & $\begin{array}{l}\text { Empresa Brasileira de } \\
\text { Aeronáutica S.A. }\end{array}$ & 07.12 .1994 & 44 & $\begin{array}{l}\text { DIST. Cosinor } \\
\text { Distribuidora S.A. }\end{array}$ & 14.11.1991 \\
\hline 21 & Embraer Aircraft Corporation & 07.12.1994 & 45 & Mafersa S.A. & 11.11.1991 \\
\hline 22 & $\begin{array}{l}\text { EAI Embraer Aviation } \\
\text { International }\end{array}$ & 07.12 .1994 & 46 & Companhia Eletromecânica & 01.11 .1991 \\
\hline 23 & $\begin{array}{l}\text { Indústria Aeronáutica Neiva } \\
\text { S.A. }\end{array}$ & 07.12.1994 & 47 & $\begin{array}{l}\text { Usinas Siderúrgicas de } \\
\text { Minas Gerais S.A }\end{array}$ & 24.10 .1991 \\
\hline 24 & Mineração Caraíba Ltda & 28.07 .1994 & 48 & Usiminas Mecânica S.A. & 24.10.1991 \\
\hline
\end{tabular}

Quadro 2 - Empresas privatizadas entre 1990 e 2005.

Fonte: MPOG (2011) 
Além disso, vale perceber a composição das companhias privatizadas no período do estudo quanto ao setor de atuação para verificar os setores com maior incidência (Gráfico 1). A partir do Gráfico 1, percebe-se que, dentre os setores definidos pelo Economática ${ }^{\circledR}$, os setores com maior representatividade na amostra são os de Finanças e Seguros, representados pelas instituições financeiras, e de Siderurgia e Metalurgia.

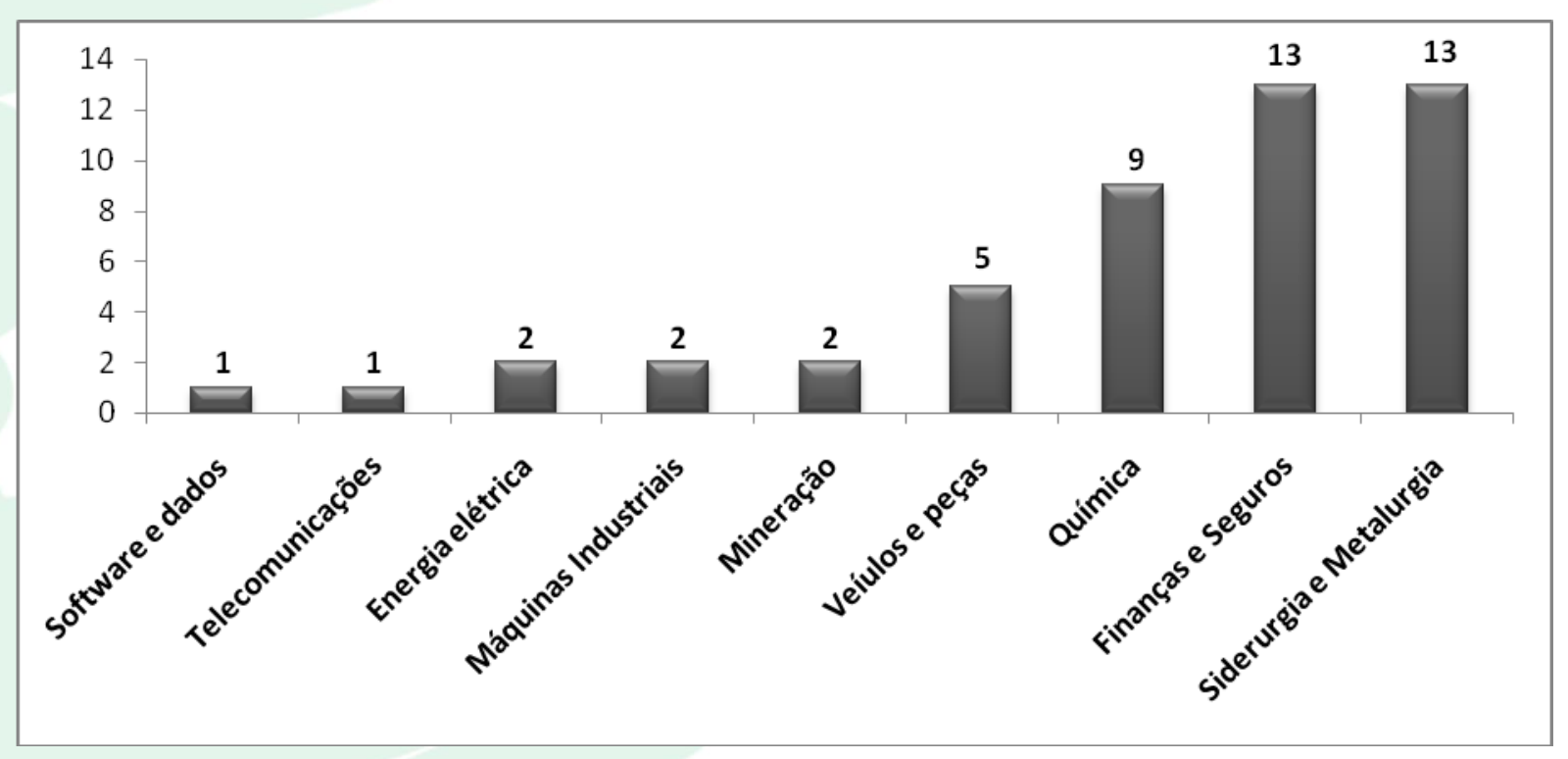

Gráfico 1 - Análise setorial de incidência de privatizações no período de 1990 a 2005.

Fonte: Elaborado pelos autores.

Videira e Luz (2009) ressaltam que o que impulsionou tal representatividade de instituições financeiras na privatização no Brasil foi a política neoliberal, na busca de reduzir a atuação do estado no mercado, assim como a má administração pública responsável pela desestruturação de diversas instituições deste setor.

Quanto ao setor de empresas siderúrgicas e metalúrgicas, Andrade, Cunha, Gandra e Ribeiro (2001) afirmam que a criação e desenvolvimento de siderúrgicas estatais no país visavam a substituição de importações e consequente diminuição da dependência de produtos manufaturados de países desenvolvidos. No entanto, a crise da dívida externa culminou no declínio da demanda do aço internamente e o excesso de capacidade decorreu em menor retorno dos produtos, que atrelado à crise não permitia o desenvolvimento das empresas deste setor. Assim, várias empresas do referido setor se privatizaram em busca de mitigar os maus resultados.

Tendo em vista a não disponibilidade de informações de alguns dados econômicos no programa Economática ${ }^{\circledR}$ das demonstrações contábeis das empresas estatais privatizadas de 1990 a 
Vanessa Ingrid da Costa Cardoso, Anna Beatriz Grangeiro Ribeiro Maia, Sandra Maria dos Santos \& Francisco de Assis Soares

2005, a amostra final ficou composta por oito empresas (ver Quadro 3). Logo, pode-se afirmar que a amostra é não probabilística, pois foi definida a partir da disponibilidade das informações necessárias para a realização do estudo econométrico (Gil, 2008).

\begin{tabular}{|c|l|c|c|}
\hline REF. & \multicolumn{1}{|c|}{ EMPRESA } & SETOR DE ATUAÇÃo & DATA DA PRIVATIZAÇÃO \\
\hline 1 & Companhia Vale do Rio Doce & Mineração & 06.05 .1997 \\
\hline 2 & Light Serviços de Eletricidade S.A. & Energia elétrica & 21.05 .1996 \\
\hline 3 & Empresa Brasileira de Aeronáutica S.A. & Veículos e peças & 07.12 .1994 \\
\hline 4 & Aço Minas Gerais & Siderurgia e Metalurgia & 10.09 .1993 \\
\hline 5 & Forjas Acesita S.A. & Siderurgia e Metalurgia & 23.10 .1992 \\
\hline 6 & Acesita Energética S.A. & Siderurgia e Metalurgia & 23.10 .1992 \\
\hline 7 & Companhia Siderúrgica de Tubarão & Siderurgia e Metalurgia & 23.07 .1992 \\
\hline 8 & Usinas Siderúrgicas de Minas Gerais S.A & Siderurgia e Metalurgia & 24.10 .1991 \\
\hline
\end{tabular}

Quadro 3 - Amostra da pesquisa

Fonte: Elaborado pelos autores.

A amostra constituinte desta pesquisa contempla, em sua maioria, empresas do setor de siderurgia e metalurgia, como se pode perceber no Quadro 3. Além disso, a data de privatização destas empresas abrange o período de 1991 a 1997. Ressalte-se que maior parte das empresas privatizadas a partir do ano de 1997, ou seja, mais de 76\% das empresas privatizadas de 1997 a 2005 são instituições financeiras, as quais não são contempladas pelo presente estudo.

\subsection{PROCEDIMENTO DE COLETA E DE ANÁLISE DE DADOS}

A coleta de dados foi realizada a partir dos dados secundários levantados no Economática ${ }^{\circledR}$ e das demonstrações contábeis das companhias. Foram analisados quatro indicadores de desempenho econômico das oito empresas constituintes da amostra. Os indicadores considerados e o respectivo cálculo são apresentados no Quadro 4. 
O Impacto da Privatização no Desempenho Econômico: Um Estudo em Empresas Brasileiras de Grande Porte

\begin{tabular}{|c|c|c|}
\hline VARIÁVEL & SIGLA & CÁLCULO \\
\hline $\begin{array}{l}\text { Economic Value Added / Valor Econômico } \\
\text { Agregado }\end{array}$ & EVA & $\begin{array}{l}\text { Lucro Líquido após os impostos - (Custo médio } \\
\text { ponderado de Capital x Capital investido, tanto } \\
\text { capital próprio como capital de terceiros) }\end{array}$ \\
\hline $\begin{array}{l}\text { Market Value Added / Valor de Mercado } \\
\text { Agregado }\end{array}$ & MVA & $\begin{array}{l}\text { Valor de mercado do capital do acionista em uma } \\
\text { determinada data (preço por ação x numero de } \\
\text { ações) - Capital investido pelos acionistas }\end{array}$ \\
\hline $\begin{array}{l}\text { Return On Equity / Retorno sobre o } \\
\text { patrimônio líquido }\end{array}$ & ROE & Lucro Líquido /Patrimônio Líquido \\
\hline Return On Assets / Retorno sobre o ativo total & ROA & Lucro Líquido/Ativo Total \\
\hline
\end{tabular}

Quadro 4 - Variáveis consideradas no estudo onte: Elaboração própria com base em Waddock e Graves (1997), Griffin e Mahon (1997), Santos e Watanab (2005), Crisóstomo, Freire e Vasconcelos (2010).

A seleção dos indicadores de desempenho econômico expostos no Quadro 4 deve-se ao fato de EVA e MVA representarem a rentabilidade real da empresa e valor acumulado, respectivamente, tendo em vista o custo de capital investido na mesma (Santos\& Watanab, 2005).

Quanto aos indicadores de rentabilidade, observa-se que os mesmos são considerados indicadores convencionais de rentabilidade empresarial. Em face à tendência atual na literatura, o presente estudo utiliza como medida de rentabilidade o ROE e o ROA (Waddock \& Graves, 1997; Griffin \& Mahon, 1997; Crisóstomo, Freire \& Vasconcellos, 2010). O ROE é geralmente utilizado pelos analistas, pois representa a medida geral de desempenho da empresa, contemplando a taxa de retorno dos recursos dos acionistas em relação aos recursos totais da empresa. Enquanto o ROA aplica-se à análise do desempenho considerando a geração de lucro em relação aos investimentos totais das empresas.

A análise dos dados do presente estudo é efetuada a partir da compilação dos dados em gráficos capazes de apresentar o comportamento do desempenho econômico das empresas antes e após sua privatização. Realizou-se ainda um teste de diferença entre médias para analisar comparativamente os desempenhos das empresas antes e após a privatização. Primeiramente, se aplicou o teste de normalidade dos dados para verificar se estes seguem uma distribuição normal e assim aplicar um teste de média. Para testar a normalidade dos dados foi efetuado o teste ShapiroWilk, que é mais apropriado para amostras pequenas, ou seja, inferiores a 30 observações (Fávero, 
Vanessa Ingrid da Costa Cardoso, Anna Beatriz Grangeiro Ribeiro Maia, Sandra Maria dos Santos \& Francisco de Assis Soares

Belfiore, Silva \& Chan, 2009). Vale ressaltar que o nível de significância considerado no presente estudo foi de $5 \%$.

Os dados coletados na pesquisa foram processados com a utilização dos softwares SPSS 20 (Statistical Package for the Social Science) e Microsoft Office Excel. Os resultados são apresentados e analisados a seguir.

\section{APRESENTAÇÃO E ANÁLISE DE RESULTADOS}

Esta seção apresenta os resultados da pesquisa quanto à análise do comportamento do desempenho econômico das empresas brasileiras frente à sua privatização.A Tabela 1 apresenta os valores referentes aos indicadores considerados, segregados de acordo com o indicador, tais como, EVA, MVA, ROE e ROA.

Tabela 1 - Desempenho econômico das empresas em estudo

\begin{tabular}{|c|l|c|c|c|c|c|}
\hline \multicolumn{1}{|l|}{ REF. } & EMPRESA & $\begin{array}{c}\text { 2 ANOS } \\
\text { ANTES }\end{array}$ & $\begin{array}{c}\text { 1 ANO } \\
\text { ANTES }\end{array}$ & $\begin{array}{r}\text { ANO DE } \\
\text { PRIVATIZAÇÃo }\end{array}$ & $\begin{array}{c}\text { 1 ANO } \\
\text { APÓS }\end{array}$ & $\begin{array}{c}\text { 2 ANOS } \\
\text { APÓS }\end{array}$ \\
\hline \multicolumn{7}{|c|}{ EVA } \\
\hline 1 & VALE & $-18,53$ & $-1,11$ & $-1,32$ & $-2,20$ & - \\
\hline 2 & LIGHT & $-8,27$ & $-23,36$ & 1,62 & 7,01 & $-3,39$ \\
\hline 3 & EMBRAER & 3,55 & 76,89 & 269,15 & 27,94 & 316,47 \\
\hline 4 & ACOMINAS & 8,21 & 2,64 & 7,68 & 12,47 & $-9,75$ \\
\hline 5 & FORJAS & $-6,26$ & 5,21 & 2,74 & 12,68 & $-2,53$ \\
\hline 6 & ACESITA & 13,56 & 1,21 & $-3,46$ & 3,68 & $-7,53$ \\
\hline 7 & CST & 6,16 & 3,21 & $-13,66$ & 4,68 & $-2,53$ \\
\hline 8 & USIMINAS & - & 13,69 & 9,18 & 3,64 & 21,48 \\
\hline
\end{tabular}


O Impacto da Privatização no Desempenho Econômico: Um Estudo em Empresas Brasileiras de Grande Porte

\begin{tabular}{|c|c|c|c|c|c|c|}
\hline \multicolumn{7}{|c|}{ MVA } \\
\hline 1 & VALE & 10,09 & 76,69 & 75,42 & 48,96 & 23,12 \\
\hline 2 & LIGHT & 4,27 & 3,63 & 12,56 & 16,63 & 6,10 \\
\hline 3 & EMBRAER & $-304,27$ & $-74,96$ & $-100,21$ & $-125,20$ & $-84,21$ \\
\hline 4 & ACOMINAS & 11,59 & 27,30 & 48,00 & 53,92 & 16,60 \\
\hline 5 & FORJAS & 50,0 & 10,52 & 27,78 & 41,71 & 61,13 \\
\hline 6 & ACESITA & 9,68 & 0,08 & 2,28 & 54,69 & 46,59 \\
\hline 7 & CST & 0,00 & 0,00 & 0,00 & 30,81 & 44,18 \\
\hline 8 & USIMINAS & - & - & 11,39 & 18,85 & 29,62 \\
\hline \multicolumn{7}{|c|}{ ROE } \\
\hline 1 & VALE & 3,13 & 5,06 & 7,98 & 10,60 & 11,91 \\
\hline 2 & LIGHT & 2,00 & $-1,65$ & 7,45 & 13,58 & 8,36 \\
\hline 3 & EMBRAER & $-323,90$ & $-73,00$ & $-112,00$ & $-160,00$ & $-90,00$ \\
\hline 4 & ACOMINAS & 4,00 & 8,70 & 5,00 & 23,00 & 12,00 \\
\hline 5 & FORJAS & 9,10 & 1,00 & 8,80 & 10,00 & 8,00 \\
\hline 6 & ACESITA & $-1,80$ & $-3,00$ & 2,60 & 1,00 & 3,00 \\
\hline 7 & CST & $-9,20$ & $-1,00$ & $-7,60$ & 2,00 & 8,00 \\
\hline 8 & USIMINAS & 40,10 & $-1,67$ & 4,97 & 9,7 & 18,80 \\
\hline & & & & & & \\
\hline
\end{tabular}


Vanessa Ingrid da Costa Cardoso, Anna Beatriz Grangeiro Ribeiro Maia, Sandra Maria dos Santos \& Francisco de Assis Soares

\begin{tabular}{|c|l|c|c|c|c|c|}
\hline 1 & VALE & 2,44 & 3,65 & 5,42 & 7,14 & 7,46 \\
\hline 2 & LIGHT & 1,80 & $-1,41$ & 5,166 & 9,03 & 3,16 \\
\hline 3 & EMBRAER & $-20,70$ & $-10,00$ & $-28,50$ & $-27,10$ & $-11,00$ \\
\hline 4 & ACOMINAS & 0,70 & 1,50 & 0,80 & 4,10 & 2,00 \\
\hline 5 & FORJAS & 6,00 & 0,70 & 5,90 & 6,80 & 5,20 \\
\hline 6 & ACESITA & $-1,00$ & $-1,70$ & 1,40 & 0,60 & 1,40 \\
\hline 7 & CST & $-7,00$ & $-0,50$ & $-5,70$ & 1,30 & 6,50 \\
\hline 8 & USIMINAS & 20,00 & $-1,00$ & 3,10 & 5,50 & 9,00 \\
\hline
\end{tabular}

Fonte: Elaborado pelos autores.

Observa-se que quando analisado dois anos antes e dois anos depois da privatização, todos os indicadores de desempenho econômico de todas as empresas, que disponibilizaram os dados financeiros a serem analisados, evoluíram em ascendência. Este resultado confronta o estudo de Saurin, Mussi e Cordioli (2000) que não demonstraram a ascendência do EVA e MVA, e corrobora com os estudos de Pinheiro (1996), de Boubakri e Cosset (1998), de D’Souza e Megginson (1999), de Pombo e Ramirez-Gomez (2003) e de Anuatti-Neto, Barossi-Filho, Carvalho e Macedo(2005), que verificaram a melhoria os indicadores financeiros das empresas frente à privatização.

Dessa forma, é relevante que os indicadores sejam individualmente analisados por meio de gráficos e ainda considerando os dois anos antes e os dois anos após a privatização. Tal análise é realizada primeiramente com o EVA, ilustrado pelo Gráfico 2. 
O Impacto da Privatização no Desempenho Econômico: Um Estudo em Empresas Brasileiras de Grande Porte

$\left.\begin{array}{rl}25,00 \\ 20,00 \\ 15,00 \\ 10,00 \\ 5,00 \\ 0,00 \\ -5,00 \\ -10,00 \\ -15,00 \\ -20,00 \\ -25,00 \\ -30,00\end{array}\right]$

Gráfico 2 - Comportamento do desempenho representado pelo EVA antes e após privatização Fonte: Elaborado pelos autores.

Os dados expressos no Gráfico 2 permitem verificar a existência de um aumento no desempenho empresarial de cinco empresas com a privatização: Vale, Light, Embraer, CST e Usiminas. Por outro lado, a Açominas, Forjas e Acesita, não obtiveram melhores resultados quanto a criação de valor após passarem pelo processo de privatização. Efetivamente, aUsiminas foi a empresa que obteve uma maior alavancagem no desempenho econômico, a qual estava com o EVA igual a zero, dois anos antes da privatização, e dois anos após a privatização conseguiu atingir valor acima de vinte. O EVA desta empresa indica que a mesma passou a criar mais valor com a sua privatização.As demais empresas sofreram uma melhora no valor do EVA, indicando que as empresas estão criando valor mais do que antes da privatização.

Em seguida, é interessante verificar o comportamento do MVA, o qual representa a criação de valor de uma empresa em relação aos recursos já investidos no negócio (Saurin,Mussi \& Cordioli, 2000). 
Vanessa Ingrid da Costa Cardoso, Anna Beatriz Grangeiro Ribeiro Maia, Sandra Maria dos Santos \& Francisco de Assis Soares

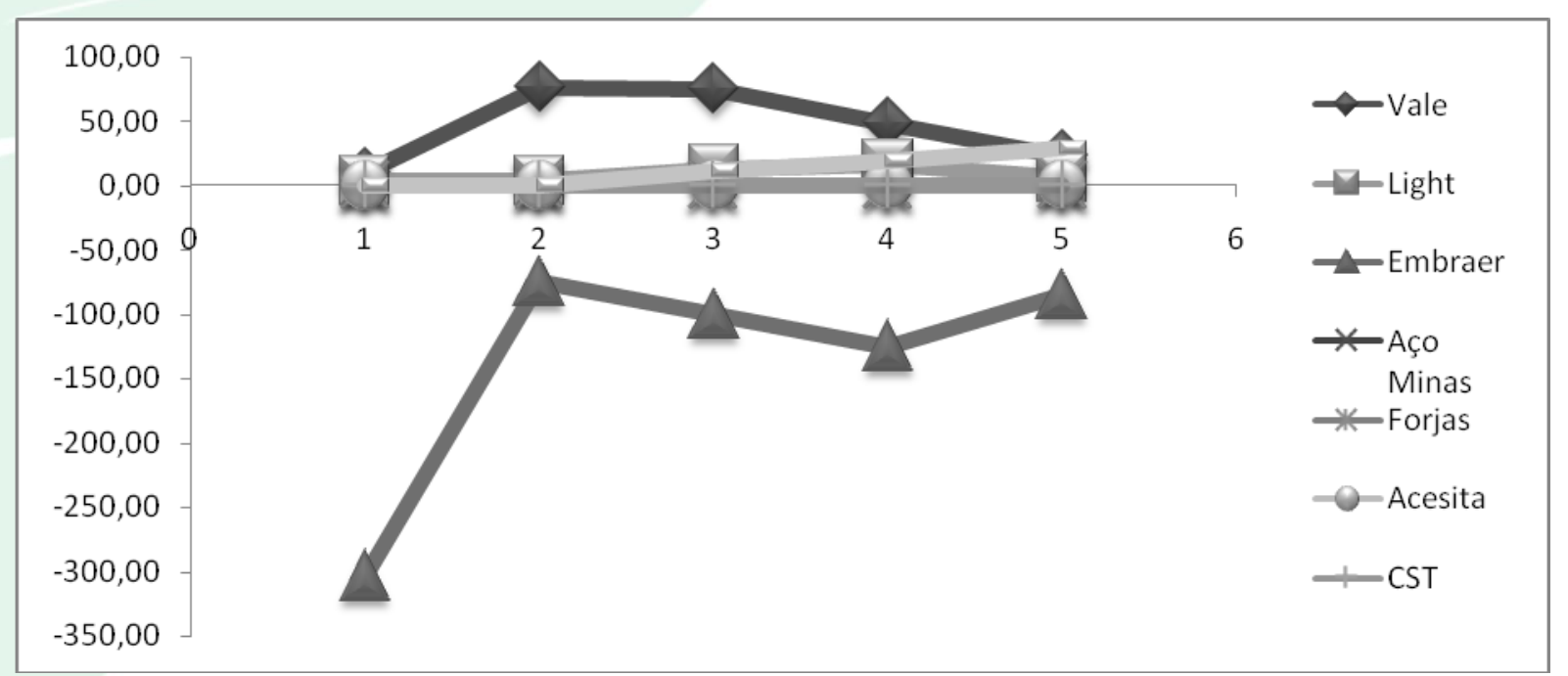

Gráfico 3 - Comportamento do desempenho representado pelo MVA antes e após privatização Fonte: Elaborado pelos autores.

Em relação ao MVA (Gráfico 3), percebe-se que que a Embraer conseguiu criar mais valor após a privatização. As outras empresas também obtiveram uma melhora, apesar de discreta. Em contraponto, a Vale, que dois anos antes da sua privatização estava criando pouco valor, obteve uma melhoria no ano seguinte. Com a privatização a empresa não obteve melhora na sua criação de valor, dado que o seu MVA declinou de forma drástica, contudo, obtendo valor mais elevado do que dois anos antes da privatização.

É fundamental também analisar a rentabilidade das empresas antes e após a privatização identificar o retorno obtido pelos investimentos efetuados. Os Gráficos 4 e 5 apresentam o desempenho medido com os indicadores econômicos ROE e ROA .

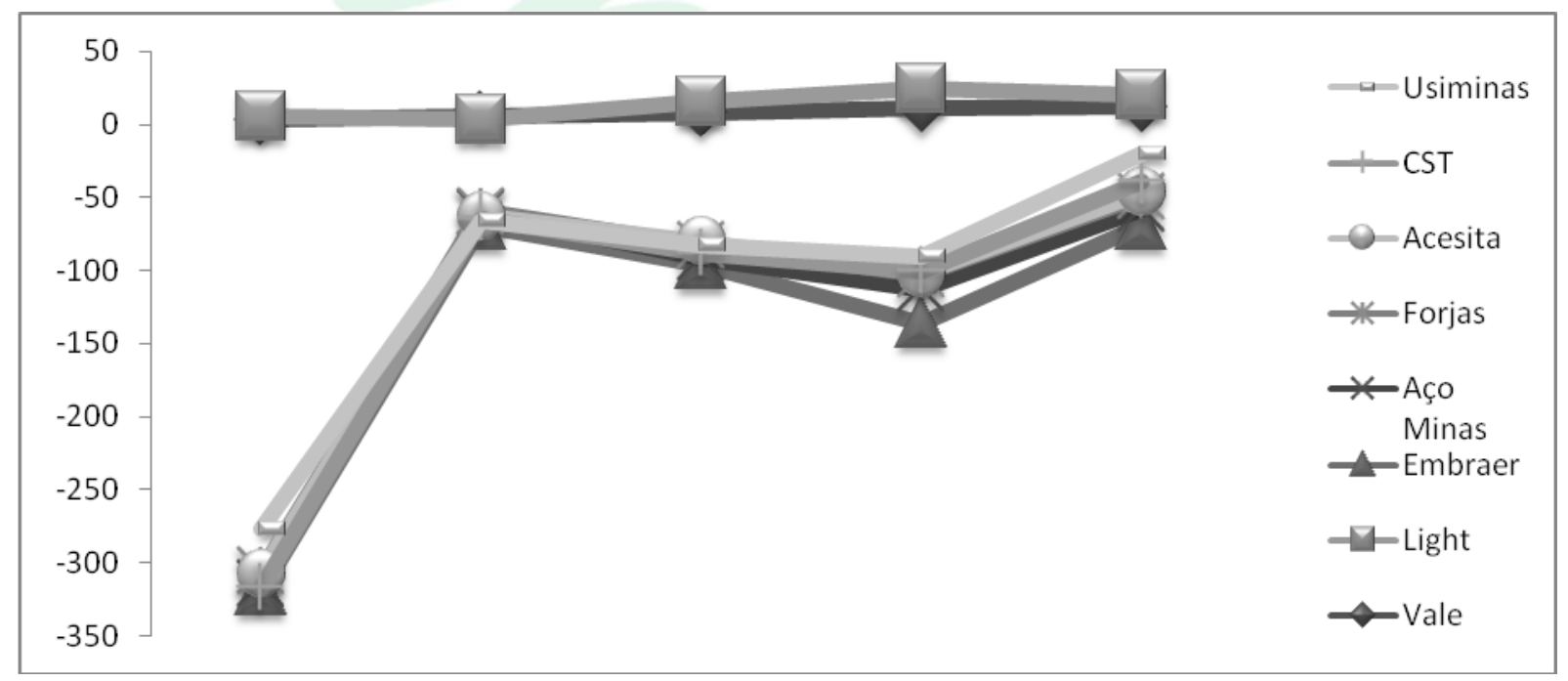

Gráfico 4 - Comportamento do desempenho representado pelo ROE antes e após privatização Fonte: Elaborado pelos autores. 
O Impacto da Privatização no Desempenho Econômico: Um Estudo em Empresas Brasileiras de Grande Porte

O Gráfico 4 ilustra a reação do retorno sobre o Patrimônio Líquido das empresas antes e após a privatização. As empresas Embraer, Aço Minas, Forjas, Acesita, CST e Usiminas comportam-se de forma semelhante e houve grande mudança nos valores referentes ao desempenho econômico antes e após a privatização. As demais empresas, Vale e Light, sofreram pequenas alterações no seu desempenho, indicando que a privatização não modificou substancialmente seus resultados e o retorno sobre o Patrimônio Líquido.O Gráfico 5 revela o retorno sobre o Ativo, que é o retorno do lucro obtido pelos recursos da empresa.

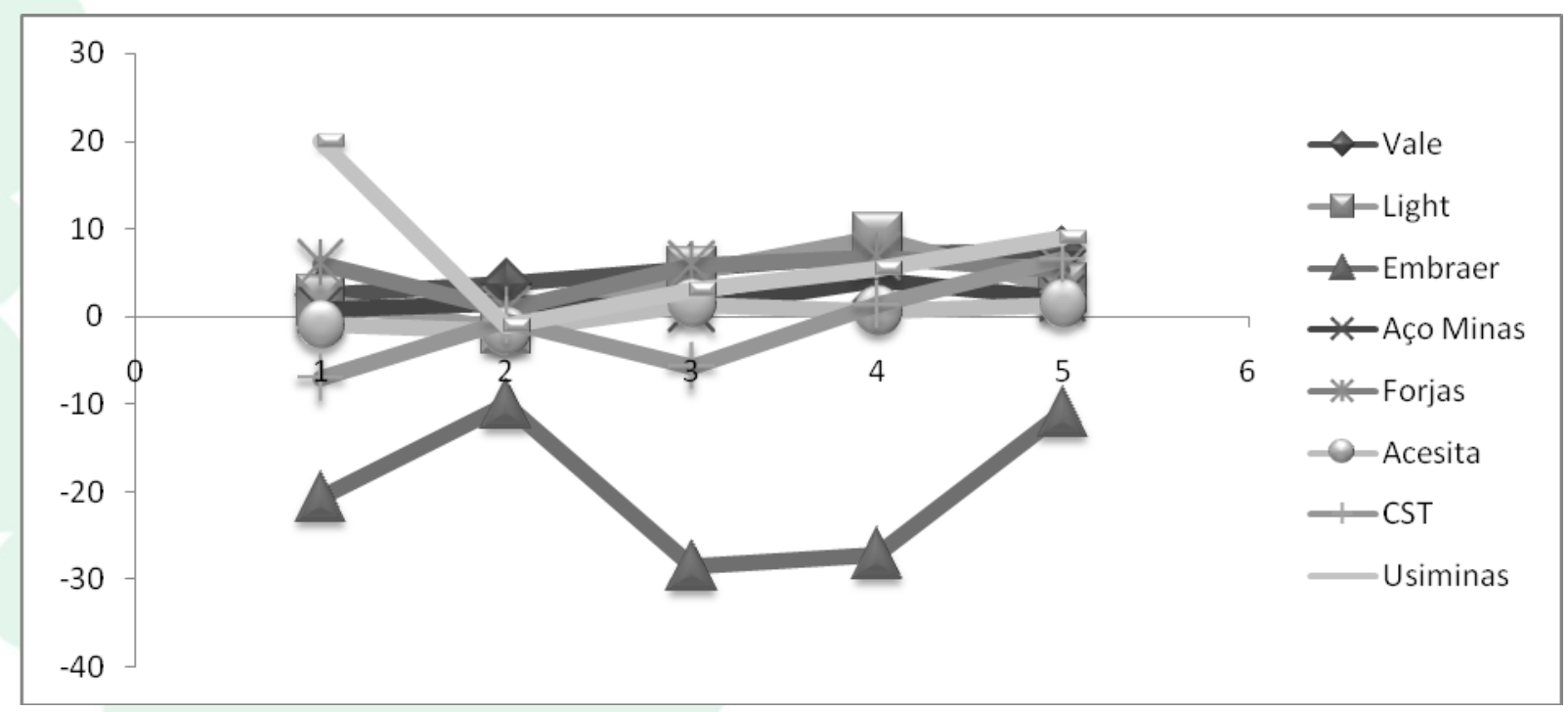

Gráfico 5 - Comportamento do desempenho representado pelo ROA antes e após privatização Fonte: Elaborado pelos autores.

Finalmente, o Gráfico 5 apresenta o comportamento do indicador ROA, que é o retorno sobre o Ativo investido das empresas. Verificamos que a diferença de rentabilidade após a privatização foi mínima. Ressalte-se o desempenho da Usiminas, que obteve valores inferiores de ROA à média da amostra, no entanto, pode-se afirmar que este resultado foi satisfatório, dado que um ano antes da privatização a empresa estava em declínio.

Em geral, entende-se que empresas de grande porte, como a Vale e a Embraer, obtiveram melhorias nos seus desempenhos após a privatização. É possível que estas mudanças alcançam a gestão da empresa tendo em vista a transferência de propriedade, o que modifica a estrutura de incentivos que têm os seus administradores, culminando na alteração do seu comportamento gerencial, afetando, assim, o desempenho da empresa (Matos Filho \& Oliveira, 1996). A mudança repentina de gerenciamento da companhia reflete-se no desempenho e mais particularmente de forma mais notória em empresas maiores do que em empresas menores, que possuem valor de 
capital mais reduzido. Além disso, é possível inferir que a privatização, nas empresas analisadas, agregou valor e possibilitou que estas obtenham maior retorno sobre os seus investimentos - o que é sustentado por a maioria das empresas analisadas apresentarem indicadores de desempenho econômico superiores aos que tinham antes da privatização.

Para complementar esta análise, realizou-se um teste de diferença entre médias, que é apresentado na Tabela 2. Primeiramente, quanto à normalidade dos dados é possível afirmar que os dados não se distribuem de forma normal. Desta forma, o teste mais apropriado, por se tratarem de distribuições não normais, é o teste não-paramétrico Mann Whitney.

Tabela 2 - Teste de Mann Whitney

\begin{tabular}{|c|c|c|}
\hline VARIÁVEL & P-VALOR & DECISÃo \\
\hline EVA & 0,014 & Rejeitar $H O$ \\
\hline MVA & 0,021 & Rejeitar $H O$ \\
\hline ROE & 0,029 & Rejeitar $H O$ \\
\hline ROA & 0,029 & Rejeitar $H O$ \\
\hline
\end{tabular}

Fonte: Elaborado pelos autores.

Com base na Tabela 2, identifica-se rejeição da Hipótese nula para todas as variáveis, a qual afirma que há similaridade estatística entre as médias dos indicadores. Tal resultado pode ser observado tendo em vista que o p-valor é menor do que o nível de significância de 5\%. Logo, podese perceber que os Indicadores econômicos são estatisticamente diferentes quando comparadas as empresas antes e após a sua privatização.

Dessa forma, com base nos resultados obtidos no presente estudo verificou-se que as empresas possuem desempenho econômico mais elevado após a sua privatização, corroborando com os estudos de Pinheiro (1996) e Anuatti-Neto, Barossi-Filho, Carvalho e Macedo (2005), que identificaram uma maior eficiência operacional, aumento da liquidez corrente e redução do endividamento de longo prazo das empresas brasileiras privatizadas, e o estudo de Pombo e Ramirez-Gomez (2003), que concluíram que as empresas estatais colombianas tiveram uma maior eficiência após a privatização. 
O Impacto da Privatização no Desempenho Econômico: Um Estudo em Empresas Brasileiras de Grande Porte

\section{CONCLUSÃO}

O presente estudo buscou analisar o comportamento do desempenho econômico das empresas brasileiras frente à privatização, utilizando uma amostra de oito empresas privatizadas no período de 1990 a 2005. Especificamente, procurámos entender se havia uma eetiva melhoria no desempenho econômico das empresas brasileiras após a privatização. Concluímos da nossa análise qualitativa dos dados econômicos das empresas que há uma melhoria, ainda que diferenciada entre empresas e usando diferentes indicadores.

As empresas foram privatizadas em anos diferentes e sabe-se que o Brasil, neste período, passou por grandes mudanças socioeconômicas. Assim, os resultados obtidos neste estudo devem ser analisados com as necessárias precauções, uma vez que fatores macroeconômicos podem criar vieses na mensuração de eventuais impactos no desempenho.

Complementarmente, a presente pesquisa agrega-se àquelas que discutem o reflexo que um processo globalmente disseminado causa nas empresas. É relevante analisar aspectos que ocorrem no contexto mundial, principalmente em um mercado peculiar como o Brasil, país de economia emergente, cujas transformações políticas implementaram diversas decisões cruciais na mudança econômica do país nesse período de tempo analisado, uma delas foi o Plano Real. Dentre as limitações do presente estudo pode-se observar que o estudo tratou de poucas empresas, o que representou aproximadamente $16 \%$ do total de empresas privatizadas, não permitindo que suas conclusões sejam generalizadas para as demais empresas. Tal limitação se deu pela indisponibilidade dos dados quanto aos anos analisados, que, na maioria das empresas, foram dados muito antigos.

Adicionalmente, vale ressaltar que outros aspectos devem ser levados em consideração para analisar a privatização e desempenho empresarial, visto que há diversos elementos intrínsecos à formação de valor das empresas e a conquista de bom desempenho, entretanto, a presente pesquisa limitou-se à verificação da privatização como uma mudança determinante na melhoria da gestão e consequente desempenho empresarial.

Dessa forma, propõe-se que estudos futuros efetuem pesquisa que contemple maior quantidade de empresas, realizando técnicas estatísticas avançadas. Além disso, recomenda-se que estudos sejam realizadas pesquisas mais detalhadas do comportamento da empresa e de características relevantes de sua gestão antes e após o processo de privatização. Análise cujo detalhamento é mais robusto pode propiciar resultados mais precisos e por isso recomenda-se que tais empresas sejam investigadas em diversos aspectos, inclusive com obtenção de dados primários com a administração das empresas privatizadas. 
Vanessa Ingrid da Costa Cardoso, Anna Beatriz Grangeiro Ribeiro Maia, Sandra Maria dos Santos \& Francisco de Assis Soares

\section{REFERÊNCIAS}

Almeida, M .H. T. (2001) La política de la privatización de las telecomunicaciones en Brasil. Revista de Economia Política, 21(2)

Andrade, L. A., Cunha, L. M. da S., Gandra G. T.\&Ribeiro, C. (2001) Impactos da Privatização no Setor Siderúrgico. BNDES Estudos Setoriais, n. 2, Rio de Janeiro: BNDES.

Andrews W., Dowling, M. (1981) Explaining performance changes in newly privatized firms. Journal of Management Studies, 35(5).

Anuatti-Neto, F.; Barossi-Filho, M.; Carvalho, A. G.; Macedo, R. (2005) Os efeitos da privatização sobre o desempenho econômico e financeiro das empresas privatizadas. Revista Brasileira de Economia, 59(2):151-175.

Baer, W. (1994) Privatization in Latin America. The World Economy, 7(4):509-528.

; Villela, A. V. (1992) Privatization and the Changing Role of the State in Brazil. In: International Congress of the Latin American Studies Association - Lasa, 17, Los Angeles. Anais... Los Angeles, CA. Disponível em: <http://lasa.international.pitt.edu/members/congresspapers/lasa1992/files/BaerWerner.pdf >. Acesso em: 07 jan. 2012.

Bernier, L. (1994) Privatization in Québec. In: Bernier, L.; Gow. A down-sized state? Québec: Presses de l'Université de Québec, 221-246.

Biondi, A. (1999)O Brasil privatizado. São Paulo: Ed. Fundação Perseu Abramo.

BNDES - Banco Nacional de Desenvolvimento. Privatização - Introdução. 2011a. Disponível em: <http://www.bndes.gov.br/SiteBNDES/bndes/bndes_pt/Institucional/BNDES_Transparente/Priv atizacao/>. Acesso em: 07 jan. 2012.

Privatização - Federais - PND. 2011b. Disponível em: <http://www.bndes.gov.br/SiteBNDES/bndes/bndes_pt/Institucional/BNDES_Transparente/Priv atizacao/pnd.html>. Acesso em: 07 jan. 2012.

Privatização - Resumo das Privatizações no Brasil. 2011c. Disponível em: <http://www.bndes.gov.br/SiteBNDES/bndes/bndes_pt/Institucional/BNDES_Transparente/Priv atizacao/resumo.html>. Acesso em: 07 jan. 2012.

Boubakri, N. \&Cosset, Jean-Claude. (1998) La privatisation tient-elle ses promesses? Le casdes pays en développement. L'actualité économique,74(3). 
Boyco, M., Shleifer A. \& VISHNY, W. (1996) A theory of privatization. The Economic Journal.

Brouthers, K. \& Arens, P. (1999) Privatization and strategic fit: evidence from Rumania. Business Strategy Review, 10(2): 53-59.

Castro, J; Meyer, G.; Strong, K. \& Uhlenbruck, N. (1996) Government objectives and organizational characteristics: a stakeholder view of privatization effectiveness. International Journal of Organizational Analysis, 4(4):373-392.

Chua, A. L. (1995) The privatization-nationalization cycle: the lynk between markets and ethnicity in developing countries. Columbia Law Review,95 (2).

Cooke, T. E. (1989) Disclosure in the corporate annual reports of Swedish companies. Accounting and Business Research,19: 113-124.

Crisóstomo, V. L.; Freire, F. de S.\& Vasconcellos, F. C. (2010) Corporate Social Responsibility, Firm Value and Financial Performance in Brazil. Social Responsibility Journal. Acesso em 09 Jan. 2012.

Dean, A., Carlisle, Y. \&Baden-Fuller, C. (1999) Punctuated and continuos change: the UK water industry. British Academy of Management.

Díaz, M. L. (2005) Globalización, grandes proyectos y privatización de la gestión urbana. Urbano,8(11): 49-58.

Dorado, S. \& Molz, R.. (1998) Privatization: The core theories and missing midlle. International Review of Administrative Sciences,64, 583-609.

Ennes, S. (1995) Privatização do setor elétrico: de volta ao futuro ou um passo para o passado? Revista de Administração de Empresas, São Paulo, 35(1): 17-22.

Fávero, L. P. L., Belfiore, P., Chan, B. L. \& Silva, F. L. da. (2009)Análise de dados: modelagem multivariada para tomada de decisões. São Paulo: Campus.

Gedajlovic, E. R. \& Shapiro, D. (1998) Management and ownership effects: evidence from five countries. Strategic Management Journal,19 (6):533-553.

Gil, A. C. (2008) Métodos e técnica de pesquisa social. São Paulo: Atlas.

Griffin, J. J. \& Mahon, J. F. (1997) The corporate social performance and corporate financial performance debate: Twenty-five years of incomparable research. Business and Society Review,36,5-31. 
Janoschka, M.. (2002) El nuevo modelo de la ciudad latinoamericana: fragmentación y privatización. EURE (Santiago), 28(85).

Labaronne, D. (1998) Les lenteurs de la privatisation en Europe de l'Est: une conséquencede la stratégie d'enracinement des managers. Revue économie politique, 108(5).

Marconi, M. de A. \&Lakatos, E. M. (2002) Técnicas de pesquisa: planejamento e execução de pesquisas, amostragens e técnicas de pesquisas, elaboração, análise e interpretação de dados. 5 . ed. São Paulo: Atlas.

Matos Filho, J. C. \&Oliveira, C. W. de A. (1996) O Processo de Privatização das Empresas Brasileiras. Texto para Discussão, IPEA, 422.

Megginson, W. L. \& D’Souza, Juliet.(1999)The financial and operation performance privatized firms during the 1990s. The Journal of Finance,54(4):1397-1438.

Megginson, W.\& Netter, J. (2001) From state to market: a survey of empirical studies on privatization. Journal of Economic Literature, 39 (2): 1-85Molz, R. \& Hafsi, T. (1997) Evaluation and assesment of privatization outcomes: a conceptual model and empirical evidence. Enviroment and planning C: Government and policy, 15, 481-495.

MPOG - Ministério do Planejamento, Orçamento e Gestão. Empresas estatais federais privatizadas desde 1990. Departamento de Coordenação e Governança das Empresas Estatais (DEST), 14 jan. 2011.

Nolan, P., Xiaoqiang, W. (1999) Beyond privatization: institutional innovation and growth in China's large state-owned enterprises. World Development, 27(1): 169-2009.

Oliva, E. de C. (2002) A privatização de empresas siderúrgicas brasileiras: reflexos na gestão de recursos humanos. RAC, 6(1): 145-161.

Özkaya, M. \&Askari, H.. (1999) Management in newly privatized companies: its importance and how little we know. World Development,27(6):1097-1114.

Parker, D. (1999) Privatization in the Europe Union: a critical assessment of its development,rationale and consequences. Economic and Industrial Democracy. 20: 9-38.

Paula, G. (1997) Avaliação do processo de privatização da siderurgia brasileira. Revista de Economia Política, 17(2): 92-109.

Pereira, L. C. B. (1997) A Reforma do Estado dos anos 90: Lógica e Mecanismos de Controle. Cadernos MARE da Reforma do Estado, Brasília, Ministério da Administração Federal e Reforma do Estado, 1. 
Pinheiro, A. \&Schneider, R.(1995) The fiscal impact of privatization in Latin America. Journal of Development Studies,31(5): 751-776.

Pinheiro, A. (1996) Impactos microeconômicos da privatização no Brasil.Pesquisa e Planejamento Econômico,26(3)).

Pombo, C. \&Ramirez-Gomez, M..(2005)Privatization in Colombia: A Plant Performance Analysis (June 30, 2003). In: CHONG, Alberto; SILANES, Florencio Lopez de. Privatization in Latin America: myths and reality. New York: World Bank.

Ramamurti, R. (1998) Why haven't countries privatized deeper and faster? World Development, 27(1).

Richardson, R. J., Peres, J. A. S., Wanderley, J. C. V., Correia, L. M.\&Peres, M. de H. M. (2009)Pesquisa social: métodos e técnicas. São Paulo: Atlas.

Rocha, Elisa M. P.; Ferreira, Marta A. T. (2001) Análise dos indicadores de inovação tecnológica no Brasil: comparação entre um grupo de empresas privatizadas e o grupo geral de empresas. Ci. Inf., Brasília,30(2):, 64-69.

Sanchis, J. A. (1996) Privatización y eficiencia en el sector público español. Revista de Economía Aplicada, 10(4): 65-92.

Santos, J. O. \& Watanab, R.. (2005) Uma Análise da Correlação entre o EVA® e o MVA® no Contexto das Empresas Brasileiras de Capital Aberto. Caderno de Pesquisas em Administração, São Paulo, 12(1): 19-32.

Saurin, V.; Mussi, C. C. \& Cordioli, L. A.(2000) Estudo do desempenho econômico das empresas estatais privatizadas com base no MVA e no EVA. Caderno de Pesquisas em Administração, 1(11): 18-26.

Serva, M.. (2003) Análise de empresas privatizadas: o desafio da multidimensionalidade. Civitas Revista de Ciências Sociais,3(2): 349-373.

Shirley, M. (1999) Bureaucrats in business: the roles of privatization versus corporatization in stateowned enterprise. World Development, 27(1): 115-136.

Silanes, F. L. de \& La Porta, R. (1999) The Benefits of Privatization: Evidence from Mexico. Quarterly Journal of Economics, 114, 1193-1242.

Stanbury, W. (1994 ) Privatization by federal and provincial governments in Canada: an empirical study. In Bernier; Gow. A down-sized state? Québec: Presses de 1'Université deQuébec, 165220. 
Vanessa Ingrid da Costa Cardoso, Anna Beatriz Grangeiro Ribeiro Maia, Sandra Maria dos Santos \& Francisco de Assis Soares

Videira, S. L.\& luz, I. (2009) A Privatização dos Bancos Estaduais no brasil. In: Encuentro de Geografos da America Latina, 12, 2009, Montevideo. Anais... Montevideo.

Voisin, C. (1995) La privatisation, une question "d'incitations" : propriété, réglementation et information. Revue Économie Politique,3(105).

Waddock, S. A. \&Graves, S. B. (1997) The corporate social performance-financial performance link. Strategic Management Journal,18:303-319.

Welch, T. \& Molz, R. (1999) Privatization governance and strategic investors: evidence from the telecommunications industry. Management International4(1): 31-41.

Recebido: 18/03/2013

Aprovado: 15/05/2013 